\title{
Mycobacteria - HIV / AIDS association
}

\author{
Morphologic findings of the tuberculosis no AIDS related in autopsies \\ practiced at the Hospital Universitario de Santander
}

Ernesto García Ayala, Alfredo Acevedo Sarmiento, Clara Inés Vargas Castellanos, Carlos Alberto García Ramírez, Orlando Augusto Olarte Ortega, Julio Alexander Díaz-Pérez y Mario Alexander Melo

Departamento de Patología, Universidad Industrial de Santander, Bucaramanga, Colombia.

INTRODUCTION: The Micobacterium tuberculosis is the main causal microorganism of the tuberculosis, is nowadays a infectious agent who causes a grand mortality in the world and Colombia. OBJECTIVE: To determinate the mayor morphological findings (macro and microscopically) of the tuberculosis no AIDS related in autopsies of the patients at the Hospital Universitario de Santander. MATERIALS AND METHODS: A prospective observational study was made, with a population that corresponds to the autopsy patients of the Hospital Universitario de Santander (729 patients). RESULTS: The diagnosis of tuberculosis no AIDS related was found in $10.66 \%$ of the cases (82 necropsies), $46.34 \%$ of them were exclusively located in the lung, $29.96 \%$ extrapulmonary and the $24.39 \%$ had mixed localization. The organ most frequently involved was de lung $70.73 \%$ followed by the pleura with $25.60 \%$, the kidney was the isolated organ most frequently compromised. Macroscopically the fibrocaseous tuberculosis witch cavitations were the most frequent form of the disease which $51.72 \%$, followed by military tuberculosis. Histologically granulomas which are constituted by giant multinucleated cells Langhans type were found in all patients. CONCLUSIONS: The tuberculosis no AIDS related is one of the principal causes of mortality in autopsy patients in the Hospital Universitario de Santander, the lung was the most affected organ and the predominant histopathological pattern was the chronic granulomatous inflammation with central caseous necrosis.

Key Words: No AIDS, fibrocaseous tuberculosis, autopsy patients.

\section{Orquirectocutanea fistula as the first manifestation of TB unrelated to AIDS}

Julio César Mantilla Hernández, Julio Alexander Díaz-Pérez, Mario Alexander Melo Uribe, Maria del Pilar Gómez Navas, Otto José Bohórquez y Álvaro Andrés Ordóñez Suárez

Departamento de Patología, Universidad Industrial de Santander, Bucaramanga, Colombia.

INTRODUCTION: The TB can compromise any organ of the body economy, which in some cases present multiple clinical manifestations, who do not allow for easy boarding diagnosis, these presentations are more common in immunocompromised patients, and are rarely observed in immunocompetent patients. AIM: To describe a case 
of a male with disseminated tuberculosis unrelated to AIDS, manifested with orquirectocutaneus fistula. CASE REPORT: Man of 47 years old, with multiple vesicular lesions in the perianal region with persistent purulent discharge of two months of evolution, with edema in penis and testis, without relevant past history. The anal carcinoma es considered and discarded through rectosigmoidoscopia which showed the presence of a anoperineal fistula with severe active inflammation and advanced internal hemorrhoids, and confirmed the presence of tuberculosis. Elisa for HIV was performed which was negative twice times. The patient starts with persistent hypoglycemia, hyponatremia and hypokalemia suspected adrenal insufficiency, does not respond to medical management and finally dies. AUTOPSY FINDINGS: Fibrocavited generalized Tuberculosis was determined in lung, lymph node, spleen, adrenal, rectal, testicular and scrotal; with orquirectocutaneus fistula. CONCLUSIONS: Spontaneous tubercular orquirectocutaneus fistulae are rare. There should be a strong clinical suspicion in endemic areas. The biopsy proves the diagnosis premortem.

Key Words: AIDS, TB orquirectocutaneus fistula.

\section{Pathological features of the tuberculosis in HIV patients at the Hospital Universitario de Santander: an autopsy study}

Julio Cesar Mantilla Hernández, Julio Alexander Díaz-Pérez

y Mario Alexander Melo Uribe

Departamento de Patologia, Universidad Industrial de Santander, Bucaramanga, Colombia.

JUSTIFICATION: Disseminated Tuberculosis (TB) is associated to advanced stages of AIDS. In these patients are frequently documented unusual forms, and the histological and microbiological diagnosis is complicated, obtaining only the diagnosis in many cases in the study postmortem. OBJECTIVE: To describe the pathological features found in 17 autopsies of patients with AIDS TB co-infection. MATERIALS AND METHODS: A descriptive study was realized; the clinical records, the autopsy protocols and the histopathology slides of the patients with AIDS- TB co infection were reviewed. All the autopsies were realized at the University Hospital of Santander from January of 2004 to June of 2008. RESULTS: 17 patients with AIDS-TB co infection were studied, which had ages between the 4 and 52 years. The average age of these patients was of $32.6 \pm 12.36$ years. The Male: female ratio was 1.8:1. All the patients had diagnosis of AIDS in stage 3C,in4patients(23,5\%)it was realized the diagnosis it was found at the compromised organs the presence of chronic inflammatory reaction with presence of granulomas imperfectly formed, with numerous neutrofils and little multinucleate giant cells, epithelioid histiocytes and zones of necrosis. In the study with ZN they documented to numerous bacilli acid alcohol resistant. CONCLUSION: Tuberculosis in patients with AIDS presents particular pathological characteristics, which are in many cases different from the presented ones in other cases of this disease. The absence of these classic characteristics contributes to the high number of cases without diagnosis premortem of this co infection.

Key Words: AIDS-TB, diagnosis of AIDS, diagnosis premortem. 